\title{
Detection and characterization of zoonotic pathogens of free-ranging non-human primates from Zambia
}

\author{
Jesca Nakayima ${ }^{1,2}$, Kyoko Hayashida ${ }^{1}$, Ryo Nakao ${ }^{3}$, Akihiro Ishii ${ }^{4}$, Hirohito Ogawa ${ }^{4}$, Ichiro Nakamura', \\ Ladslav Moonga ${ }^{5}$, Bernard M Hang'ombe ${ }^{5}$, Aaron S Mweene ${ }^{6}, Y_{\text {Yka Thomas }}{ }^{4}$, Yasuko Orba ${ }^{7}$, Hirofumi Sawa ${ }^{7 *}$ \\ and Chihiro Sugimoto ${ }^{1 *}$
}

\begin{abstract}
Background: Wildlife may harbor infectious pathogens that are of zoonotic concern acting as a reservoir of diseases transmissible to humans and domestic animals. This is due to human-wildlife conflicts that have become more frequent and severe over recent decades, competition for the available natural habitats and resources leading to increased human encroachment on previously wild and uninhabited areas.

Methods: A total of 88 spleen DNA samples from baboons and vervet monkeys from Zambia were tested for zoonotic pathogens using genus or species-specific PCR. The amplified products were then subjected to sequencing analysis.

Results: We detected three different pathogenic agents, including Anaplasma phagocytophilum in 12 samples (13.6\%), Rickettsia spp. in 35 samples (39.8\%) and Babesia spp. in 2 samples (2.3\%).

Conclusion: The continuously increasing contacts between humans and primate populations raise concerns about transmission of pathogens between these groups. Therefore, increased medical and public awareness and public health surveillance support will be required to detect and control infections caused by these agents at the interface between humans and wildlife.
\end{abstract}

Keywords: Non-human primates, Reservoir, Pathogens, Zoonosis, Zambia

\section{Background}

Wildlife poses a threat as a potential source of emerging infectious diseases (EIDs) to biodiversity conservation as well as human health. Three quarters of zoonotic EIDs are caused by pathogens in wildlife and the incidence of such diseases is increasing significantly in humans $[1,2]$. Human activities have contributed to a closer contact between humans and wildlife due to a complex relationship between social and environmental factors causing a major threat both to human health and biodiversity conservation mainly through disease transmission between the two groups [3-5].

\footnotetext{
* Correspondence: h-sawa@czc.hokudai.ac.jp; sugimoto@czc.hokudai.ac.jp ${ }^{7}$ Division of Molecular Pathobiology, Research Center for Zoonosis Control, Hokkaido University, N20, W10, Kita-ku, Sapporo 001-0020, Japan

'Division of Collaboration and Education, Research Center for Zoonosis Control, Hokkaido University, Kita 20, Nishi 10, Kita-ku, Sapporo, Hokkaido 001-0020, Japan

Full list of author information is available at the end of the article
}

The Order Primates has traditionally been divided into two main groupings: prosimians and anthropoids (simians). Non-human primates (NHPs) are a diverse group of animals. Generally, Old World monkeys (Catirrhini) and apes (Hominoidea) are those found in Africa, the Indian subcontinent and in East Asia. New World or neotropical NHPs (Platirrhini) are found in South and Central America. In Zambia, baboons and vervet monkeys are the major non-human primates not only in wildlife management regions, but even out of the management areas. Humanmonkey conflicts in the form of crop damage, grabbing of personal effects and direct injury are reported [6].

Several hundred infectious diseases are classified as zoonotic diseases as they are caused by bacteria, viruses, fungi, prions or parasites that can be transmitted from animals to humans and vice versa [7]. Transmission can be direct or indirect, via another organism, either a vector or an intermediate host. Invertebrates spread pathogens 
by two main mechanisms, either through their bite, or their feces, thus, transmission occurring mechanically or biologically. Tick-borne microbial pathogens, which cause human and zoonotic diseases such as Lyme disease, anaplasmosis, ehrlichiosis, babesiosis, Q ("query") fever, tickborne encephalitis, Crimean-Congo hemorrhagic fever, Rocky Mountain spotted fever, Colorado tick fever, tick typhus and tularemia, have enormous negative impacts on human health and economic development worldwide. Other zoonotic disease vectors include tsetse flies (Glossina spp.) transmitting trypanosomiasis, sand flies (Phlebotomus spp.) transmitting leishmaniasis and mosquitoes (Culicidae spp.) transmitting malaria.

The hotspots of zoonotic disease transmission include livestock markets, urban and peri-urban wildlife and farming on fragments and edges of wildlife conservation areas and buffer zones. We hypothesized that a possible interaction between human and simian pathogens coming from a zoonotic cycle cannot be disregarded because simians that live in the areas of the disease endemic foci of Africa could play a role as reservoir for urban cycle disease transmission.

Therefore, we undertook a study of the sylvatic cycle zoonotic pathogens that can threaten humans in Zambia.
The pathogens tested here included: Anaplasma spp., Trypanosoma spp., Rickettsia spp., Coxiella burnetii, Leishmania spp., Babesia spp., Plasmodium spp., Ehrlichia spp. and Borrelia spp. in African NHPs.

\section{Methods}

\section{Sample collection and DNA extraction}

Spleen samples were obtained from 48 yellow baboons (Papio cynocephalus) and 40 vervet monkeys (Chlorocebus pygerythrus) in 2008. The sampling was conducted at Mfuwe in South Luangwa National park, Zambia (13 $14^{\prime}$ $42.00^{\prime \prime} \mathrm{S}, 31^{\circ} 38^{\prime} 54.07^{\prime \prime}$ E) (Figure 1). Eighty eight spleen DNA samples were analyzed in the current study for Anaplasma spp., T. brucei rhodesiense and T. brucei gambiense, Rickettsia spp., Coxiella burnetii, Leishmania spp., Plasmodium spp., Babesia spp., and Borrelia spp. DNA was extracted from these organs by using the QIAamp DNA Mini Kit (Qiagen, Valencia, CA) according to the manufacturer's instructions.

\section{Ethical clearance}

The culling was conducted under the permission from the Zambia Wildlife Authority (ZAWA) and the Institutional

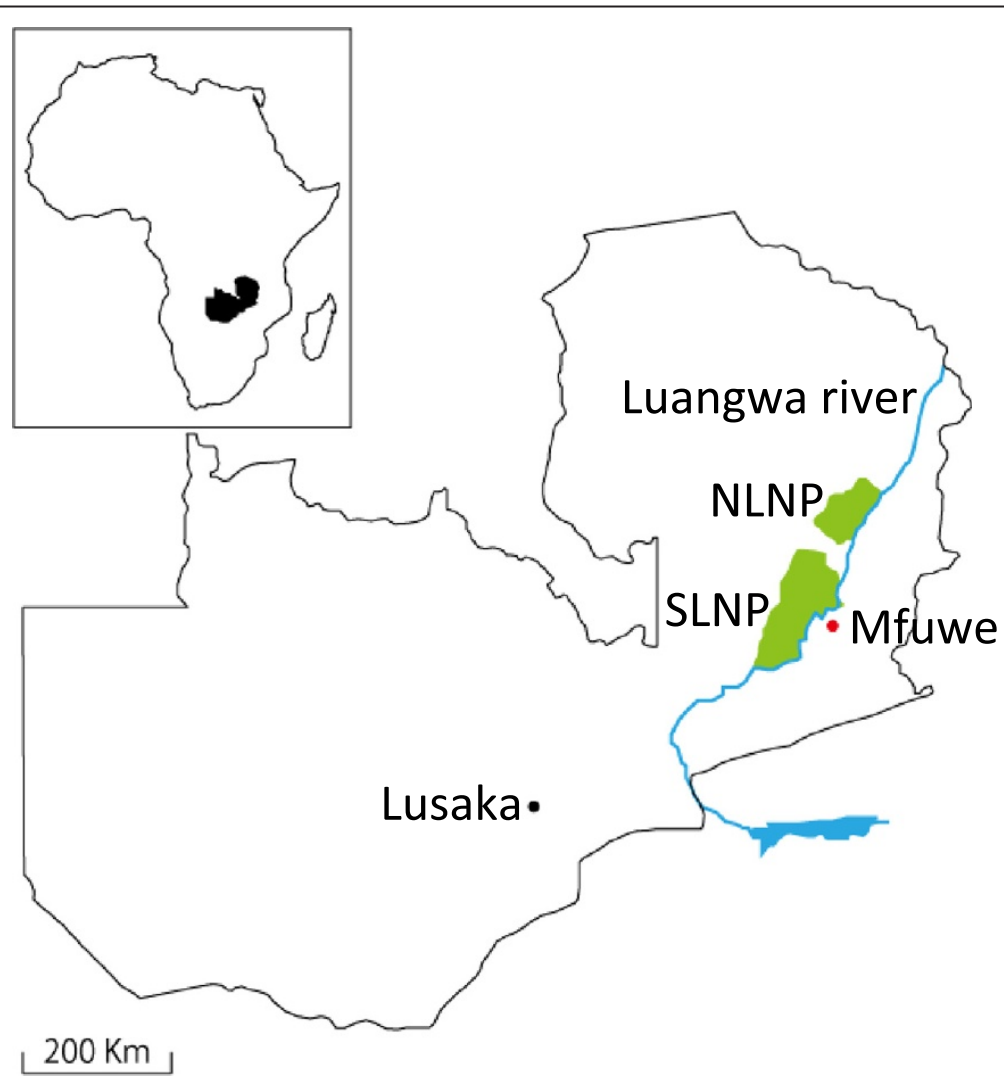

Figure 1 Map of Zambia showing the sampling site. NLNP: North Luangwa National Park, SLNP: South Luangwa National Park of the Luangwa valley ecosystem a Human African Trypanosomiasis (HAT) focus. 
Ethical and Animal Care guidelines were adhered to during the culling and sampling exercise.

\section{Molecular identification of pathogens $P C R$ amplifications}

PCR reactions were conducted using Amplitaq Gold 360 reagent (Applied Biosystems, Foster City, CA) in a $20 \mu \mathrm{l}$ reaction volume. All the primer sets employed in this study and PCR conditions can be found in Table 1 [8-15]. The PCR products were electrophoresed in a $1.5 \%$ agarose gel stained with Gel-Red (Biotium, Hayward, CA) and were visualized under UV light.

\section{Sequencing}

The amplified PCR products for Babesia spp. Rickettsia spp. and Anaplasma spp. were subjected to direct sequencing and phylogenetic analysis. The amplicons were treated with ExoSAP-IT (USB Corporation, Cleveland, $\mathrm{OH}$ ). The sequencing reaction was carried out with the BigDye terminator kit version 3.1 and resolved with a $3130 \mathrm{ABI}$ (Applied Biosystems) capillary sequencer. The DNA sequences obtained were submitted to the DNA Data Bank of Japan (DDBJ) (http://www.ddbj.nig.ac.jp) under accession nos. AB844434 to AB844437. Phylogenetic analysis of the pathogens ( $R$. africae:A, $426 \mathrm{bp}, 16 \mathrm{~S}$ rRNA; $A$. phagocytophilum:B, 345 bp 16S rRNA and B. microti:C, 238 bp, $18 \mathrm{~S}$ rRNA) detected in primates from Zambia was based on $16 \mathrm{~S}$ rRNA or $18 \mathrm{~S}$ rRNA sequences respectively. The tree was constructed using the neighbor-joining method and ClustalW alignment.

\section{Statistical analysis}

Statistical analysis of prevalence data was done using Chi-square statistical test. The chi-square test was meant to test the null hypothesis, which states that there is no significant difference between the expected and observed result.

\section{Results}

PCR assays using genus- or species-specific primers for the selected zoonotic pathogens detected Rickettsia spp. in 35 samples (39.8\%), Anaplasma spp. in 12 samples (13.6\%) and Babesia spp. in 2 samples (2.3\%). However, Borrelia spp., Trypanosoma spp., Plasmodium spp., Leishmania spp., and Coxiella burnetii were not detected. Important to note, Babesia spp. was only detected in baboons (Table 2). There was no significant difference between the infection prevalence, primate species and sex

Table 1 Primers and conditions for PCR detection of pathogen DNA

\begin{tabular}{|c|c|c|c|c|c|c|}
\hline Organism & Target gene & Primer & Sequence ( $5^{\prime}$ to $\left.3^{\prime}\right)$ & $\begin{array}{l}\text { Amplicon } \\
\text { size (bp) }\end{array}$ & $\begin{array}{l}\text { Annealing } \\
\text { temperature }\left({ }^{\circ} \mathrm{C}\right)\end{array}$ & Reference \\
\hline \multirow[t]{3}{*}{ Rickettsia spp } & gltA & RpCS.780p & GACCATGAGCAGAATGCTTCT & 600 & 48 & {$[8]$} \\
\hline & & RpCS.877p & GGGGACCTGCTCACGGCGG & 480 & 54 & \\
\hline & & RpCS.1273r & CATAACCAGTGTAAAGCTG & & & \\
\hline \multirow[t]{2}{*}{ Anaplasma sp.. } & $16 \mathrm{~S}$ rDNA & EHR16SD & GGTACCYACAGAAGAAGTCC & 345 & 53 & {$[9]$} \\
\hline & & EHR16SR & TAGCACTCATCGTITACAGC & & & \\
\hline \multirow[t]{2}{*}{ Coxiella burnetii } & IS1111 & Trans 1 & TATGTATCCACCGTAGCCAGTC & 687 & 60 & {$[10]$} \\
\hline & & Trans 2 & CCCAACAACACCTCCTTATTC & & & \\
\hline \multirow[t]{4}{*}{ Borrelia spp. } & fla gene & BflaPAD & GATCA(G/A)GC(T/A)CAA(C/T)ATAACCA(A/T)ATGCA & & 55 & [11] \\
\hline & & BflaPDU & AGATTCAAGTCTGTITGGAAAGC & & & \\
\hline & & BflaPBU,nest & GCTGAAGAGCTTGGAATGCAACC & 340 & 55 & \\
\hline & & BflaPCR,nest & TGATCAGTTATCATTCTAATAGCA & & & \\
\hline \multirow[t]{2}{*}{ B. microti } & $18 \mathrm{~S}$ rDNA & Babl & CTTAGTATAAGCTITATACAGC & 238 & 55 & {$[12]$} \\
\hline & & Bab4 & ATAGGTCAGAAACTTGAATGATACA & & & \\
\hline \multirow[t]{2}{*}{ Trypanosoma spp. } & ITS1 rDNA & ITS1 CF & CCGGAAGTTCACCGATATTG & Variable & 58 & {$[13]$} \\
\hline & & ITS1 BR & TTGCTGCGTTCTTCAACGAA & & & \\
\hline \multirow[t]{2}{*}{ Leishmania spp. } & kDNA minicircle & L.MC-1S & CTRGGGGTTGGTGTAAAATAG- & 700 & 55 & {$[14]$} \\
\hline & & L.MC-1R & TWTGAACGGGRTTTCTG & & & \\
\hline \multirow[t]{4}{*}{ Plasmodium spp. } & Cytb & DW2 \&DW4 & DW2; TAATGCCTAGACGTATTCCTGATTATCCAG & 1253 & 60 & {$[15]$} \\
\hline & & & DW4; TGITTGCTTGGGAGCTGTAATCATAATGTG & & & \\
\hline & & Cytb1 \& Cytb2 & CYTb1; CTCTATTAATITAGTTAAAGCACA & 939 & 50 & \\
\hline & & & Tb2; ACAGAATAATCTCTAGCACC & & & \\
\hline
\end{tabular}


Table 2 The prevalence of zoonotic pathogens in non-human primates in Zambia

\begin{tabular}{|c|c|c|c|c|c|c|}
\hline & \multicolumn{3}{|c|}{ Baboon $(n=48)$} & \multicolumn{3}{|c|}{ Vervet monkey $(n=40)$} \\
\hline & \multicolumn{2}{|c|}{ Sex } & \multirow[t]{2}{*}{ Sub-total (\%) } & \multicolumn{2}{|c|}{ Sex } & \multirow[t]{2}{*}{ Sub-total (\%) } \\
\hline & $\begin{array}{l}M \\
(39)\end{array}$ & $\begin{array}{l}F \\
(9)\end{array}$ & & $\begin{array}{l}M \\
(33)\end{array}$ & $\begin{array}{l}F \\
\text { (7) }\end{array}$ & \\
\hline $\begin{array}{l}\text { Anaplasma } \\
\text { spp. }\end{array}$ & 3 & 2 & $5(10.4 \%)$ & 6 & 1 & $7(17.5 \%)$ \\
\hline Babesia spp. & 1 & 1 & $2(4.2 \%)$ & 0 & 0 & 0 \\
\hline Borrelia spp. & & & 0 & & & 0 \\
\hline Coxiella burnetii & & & 0 & & & 0 \\
\hline $\begin{array}{l}\text { Leishmania } \\
\text { spp. }\end{array}$ & & & 0 & & & 0 \\
\hline $\begin{array}{l}\text { Plasmodium } \\
\text { spp. }\end{array}$ & & & 0 & & & 0 \\
\hline Rickettsia spp. & 14 & 2 & $16(33.3 \%)$ & 15 & 4 & $19(47.5 \%)$ \\
\hline $\begin{array}{l}\text { Trypanosoma } \\
\text { spp. }\end{array}$ & & & 0 & & & 0 \\
\hline
\end{tabular}

of the primates as tested by Chi square test (data not shown). Information on age of the primates was not available.

Some of the positive samples with genus-specific primers were further subjected to direct sequencing and the BLAST sequence homology searches were performed. Two Rickettsia spp.-positive samples had 99\% identity with $R$. africae from Nigerian ticks [16]. Two Anaplasma spp.-positive samples were sequenced and showed 100\% similarity with $A$. phagocytophilum from various host species and geographical regions. Two Babesia spp.-positive samples from baboons showed the highest sequence similarity with Babesia spp. KMG-2009a from baboons with $100 \%$ identities, and also showed $98 \%$ similarity with $B$. leo-K8, the isolate from a domestic cat in South Africa, and $99 \%$ similarity with Babesia spp. from a laboratory raised baboon in USA [17].

\section{Discussion}

An investigation of pathogens in wild NHPs found in habitats close to human settlements is of importance in the control and eradication of probable human zoonotic pathogens.

We detected Rickettsia spp. in a total of 35 samples (39.8\%). Further sequencing analysis revealed that some of the sequences were highly similar to that of $R$. africae (Figure 2). This is an agent of African tick bite fever, an acute and flu-like illness that is frequently accompanied by severe headache, inoculation eschars with regional lymphadenitis, vesicular cutaneous rash, and aphthous stomatitis $[18,19]$. The disease is transmitted in rural sub-Saharan Africa by ungulate ticks of the Amblyomma genus, mainly Amblyomma hebraeum in southern Africa and Amblyomma variegatum in west, central, and east
Africa [20]. Phylogenetic comparisons between our obtained sequence and previous studies worldwide revealed a close relationship between Zambian and Nigerian $R$. africae isolates, suggesting general occurrence of rickettsioses in African continent.

We also obtained the sequences associated with $A$. phagocytophilum from both baboons and vervet monkeys (Figure 2). A. phagocytophilum, an obligate intracellular bacterium, is the agent of human granulocytic anaplasmosis, formerly known as human granulocytic ehrlichiosis [21]. This bacterium can infect humans and numerous animal species, including horses, cats, dogs, ruminants, and wildlife. In our analysis of A. phagocytophilum $16 \mathrm{~S}$ rRNA gene, we found that the sequences of $16 \mathrm{~S}$ rRNA were very conserved not only between African isolates but also between the other isolates of world-wide origin and this was in agreement with previous studies [22].

The rodent parasite $B$. microti and the bovine pathogen Babesia divergens appear to be responsible for virtually all of the known human zoonotic Babesia cases [23,24]. We detected a $B$. microti-like parasite from Zambian primates at a prevalence of $2.3 \%$ from baboons. Because B. microti shares a vertebrate host reservoir, the white-footed mouse (Peromyscus leucopus) and tick vector (Ixodes dammini) with $B$. burgdorferi, it might be expected that the caseload for human babesiosis will parallel the rise in the number of cases of Lyme disease in endemic areas [25-27].

Babesia microti, long considered on morphological grounds to be a single species found only in rodents, is now thought to consist of a complex of closely related subspecies, many of which are found in non-rodent hosts. Goethert and Telford III [28] identified 3 clades based on analysis of the 18S rRNA and beta-tubulin genes, with one (Clade 1) containing the majority of strains thought to be zoonotic. This clade includes the American zoonotic strains that have caused most babesiosis cases worldwide, but there are also separate zoonotic strains occurring in Japan ('Kobe' and 'Hobetsu') and Taiwan [29]. Strains of unknown zoonotic potential but closely related to the zoonotic American strains, according to $18 \mathrm{~S}$ rRNA or betatubulin gene analysis, have been isolated in Germany (Hannover), central and eastern Russia (Mis, near Berezniki, Perm region and Vladivostok), Japan, South Korea and north-east China (Xinjiang) [28,30-32]. The zoonotic potential of Zambian B. microti-like parasite found calls for further investigation.

The genus Borrelia comprises of 37 known species of which 12 species are known to cause Lyme disease and are transmitted by ticks. Borrelia burgdorferi sensu lato complex, which is related to Lyme disease, is classified into four genospecies on the basis of genetic, phenotypic, and immunological properties [33]. The endemic tick-borne relapsing fever spirochetes are transmitted through the bites of soft ticks of the genus Ornithodoros; O. sonrai serves as 


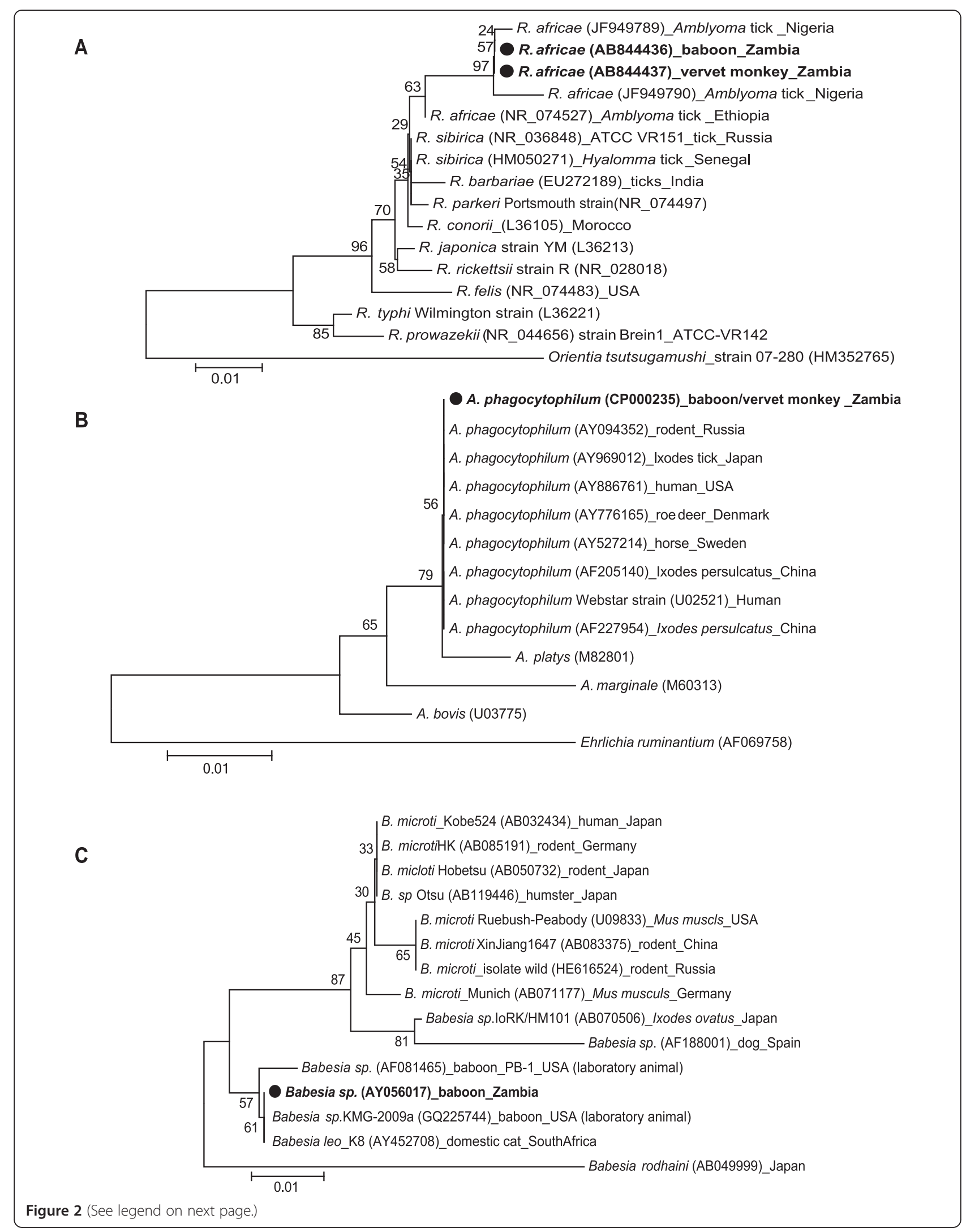


(See figure on previous page.)

Figure 2 Phylogenetic positions of the pathogens (R. africae: A, 426 bp, 16S rRNA; A. phagocytophilum: B, $345 b p$ 16S rRNA and B. microti C, 238bp, 18S rRNA) detected in primates from Zambia based on 16S rRNA or 18S rRNA sequences respectively. The tree was constructed using the neighbor-joining method and ClustalW alignment, and numbers on the tree indicate 1000 bootstrap values for branch points. Accession numbers are indicated.

the principle vector for Borrelia crocidurae in West Africa, and O. moubata complex ticks effectively maintain these spirochetes in East Africa [34]. Borrelia recurrentis causes louse-borne relapsing fever and $B$. duttonii is the agent of East African tick-borne relapsing fever [35]. Some cases of Lyme disease have been reported in Kenya [36], but any Borrelia species were not detected in our study.

Although we have included several other pathogens, which have the potential for causing zoonoses, we could not detect those species in this study. Trypanosomes infect a wide range of wildlife species that constitute a reservoir of infection for both people and domestic animals. In Zambia, human African trypanosomiasis, caused by T. brucei rhodesiense, is endemic especially alongside the Luangwa Valley ecosystem [37]. However, active trypanosome infection was not demonstrated in sampled NHPs in our study, although the Luangwa Valley ecosystem is an active trypanosomiasis endemic focus with several human cases having been reported from the same area [38], and vervet monkeys are experimentally susceptible to African salivarian trypanosomes T. b. rhodesiense [39,40] and T. b. gambiense [41].

Plasmodium spp. was not detected in the current study. So far, the transmission of $P$. knowlesi, a malaria parasite of Southeast Asian macaques occurs from monkeys to humans in South-East Asia [42]. Coexistence of humans and monkeys in the same habitat has been driven in some cases by ecological conditions as observed in the transmission of $P$. knowlesi to the human population in Southeast Asia [43]. Recently, several additional Plasmodium species such as $P$. cynomologi, $P$. inui, $P$. simium, and $P$. brasilianum have been considered to be the zoonotic parasites from monkey to human, but none of them have been reported in Africa. Therefore, several authors hypothesized that monkeys may act as reservoirs for human malaria or vice versa [43]. In the wild, baboons harbour parasites closely related to Plasmodium, such as Hepatocystis spp., but they are not naturally susceptible to Plasmodium [44].

To the best of our knowledge, this is the first report of these potential zoonotic pathogens detected in non-human primates in Zambia. Therefore, zoonotic infections namely: human Babesiosis, Anaplasmosis and Rickettsiosis are suspected to be endemic in Zambia in humans and cases could be simply misdiagnosed especially as malaria due to the febrile nature of the illnesses.

\section{Conclusion}

Our study revealed that, potential zoonotic pathogens; $R$. africae, A. phagocytophilum and B. microti-like parasites exist in Zambian non-human primates. Zoonosis transmission involves interplay between humans, livestock and wildlife, making disease control complicated due to the lack of knowledge of the roles played by each. Better understanding of zoonotic pathogens harbored in nonhuman primates is necessary and must be adopted as a control measure in all regions inhabited by these animals or where they are in close proximity with human beings.

\section{Abbreviations}

EID: Emerging infectious diseases; NHP: Non-human primates; ZAWA: Zambia Wildlife Authority; TG: Typhus group; SFG: Spotted fever group.

\section{Competing interests}

The authors declare that they have no competing interests.

\section{Authors' contributions}

$\mathrm{HS}$ and CS designed the study and performed data analysis. Al, HO, IN, LN, $\mathrm{BMH}, \mathrm{AM}, \mathrm{YT}$ and $\mathrm{YO}$ performed sample collection and processing. $\mathrm{YO}$ and AM identified research areas and contributed to obtaining the ethical clearance. JN, KH, RN and CS wrote the manuscript and all authors edited the manuscript. All authors read and approved the final manuscript.

\section{Acknowledgements}

This work was supported by the program of Funding Research Center for Emerging and Re-emerging Infectious Disease from Ministry of Education, Culture, Sports, Science and Technology of Japan (MEXT). We thank the Zambia Wildlife Authority (ZAWA) for supporting this research.

\section{Author details}

${ }^{1}$ Division of Collaboration and Education, Research Center for Zoonosis Control, Hokkaido University, Kita 20, Nishi 10, Kita-ku, Sapporo, Hokkaido 001-0020, Japan. ${ }^{2}$ National Livestock Resources Research Institute (NaLIRRI), P. O. Box 96, Tororo, Uganda. ${ }^{3}$ Unit of Risk Analysis and Management, Research Center for Zoonosis Control, Hokkaido University, Kita 20, Nishi 10, Kita-ku, Sapporo, Hokkaido 001-0020, Japan. ${ }^{4}$ Hokudai Center for Zoonosis Control in Zambia, School of Veterinary Medicine, University of Zambia, PO Box 32379 Lusaka, Zambia. ${ }^{5}$ Department of Paraclinical Studies, School of Veterinary Medicine, University of Zambia, PO Box 32379 Lusaka, Zambia. ${ }^{6}$ Department of Disease Control, School of Veterinary Medicine, University of Zambia, PO Box 32379, Lusaka, Zambia. ${ }^{7}$ Division of Molecular Pathobiology, Research Center for Zoonosis Control, Hokkaido University, N20, W10, Kita-ku, Sapporo 001-0020, Japan.

Received: 25 February 2014 Accepted: 13 October 2014 Published online: 29 October 2014

\section{References}

1. Kooriyama T, Okamoto M, Yoshida T, Nishida T, Tsubota T, Saito A, Tomonaga M, Matsuzawa T, Akari H, Nishimura H, Miyabe-Nishiwaki T: Epidemiological study of zoonoses derived from humans in captive chimpanzees. Primates 2013, 54:89-98.

2. Bekker JL, Hoffman LC, Jooste PJ: Wildlife-associated zoonotic diseases in some southern African countries in relation to game meat safety: A review. Onderstepoort J Vet Res 2012, 79:E1-E12.

3. Kaiser J: Conservation biology. Ebola, hunting push ape populations to the brink. Science 2003, 300:232.

4. Whitfield J: The law of the jungle. Nature 2003, 421:8-9.

5. Kondgen S, Kuhl H, N'Goran PK, Walsh PD, Schenk S, Ernst N, Biek R, Formenty P, Matz-Rensing K, Schweiger B, Junglen S, Ellerbrok H, Nitsche A, Briese T, Lipkin WI, Pauli G, Boesch C, Leendertz FH: Pandemic human 
viruses cause decline of endangered great apes. Curr Biol 2008, 18:260-264.

6. Chomba C, Senzota R, Chabwela H, Mwitwa J, Nyirenda V: Patterns of human - wildlife conflicts in Zambia, causes, consequences and management responses. J Ecol Nat Environ 2012, 4:303-313.

7. Lloyd-Smith JO, George D, Pepin KM, Pitzer VE, Pulliam JRC, Dobson AP, Hudson PJ, Grenfell BT: Epidemic dynamics at the human-animal interface. Science 2009, 326:1362-1367.

8. Ishikura M, Ando S, Shinagawa Y, Matsuura K, Hasegawa S, Nakayama T, Fujita $H$, Watanabe $M$ : Phylogenetic analysis of spotted fever group rickettsiae based on gltA, 17-kDa, and rOmpA genes amplified by nested PCR from ticks in Japan. Microbiol Immunol 2003, 47:823-832.

9. Parola P, Roux V, Camicas $U$, Baradji I, Brouqui P, Raoult D: Detection of Ehrlichiae in African ticks by polymerase chain reaction. Trans $R$ Soc Trop Med Hyg 2000, 94:707-708.

10. Parisi A, Fraccalvieri R, Cafiero M, Miccolupo A, Padalino I, Montagna C, Capuano F, Sottili R: Diagnosis of Coxiella burnetii-related abortion in Italian domestic ruminants using single-tube nested PCR. Vet Microbiol 2006, 118:101-106.

11. Takano A, Goka K, Une Y, Shimada Y, Fujita H, Shiino T, Watanabe H, Kawabata H: Isolation and characterization of a novel Borrelia group of tick-borne borreliae from imported reptiles and their associated ticks. Environ Microbiol 2010, 12:134-146.

12. Persing DH, Mathiesen D, Marshall WF, Telford SR, Spielman A, Thomford JW, Conrad PA: Detection of Babesia microti by polymerase chain reaction. J Clin Microbiol 1992, 30:2097-2103.

13. Njiru ZK, Constantine CC, Guya S, Crowther J, Kiragu JM, Thompson RCA Da'vila AMR: The use of ITS1 rDNA PCR in detecting pathogenic African trypanosomes. Parasitol Res 2005, 95:186-192.

14. Kato H, Uezato H, Gomez EA, Terayama Y, Calvopiña M, Iwata H, Hashiguchi $Y$ : Establishment of a mass screening method of sand fly vectors for Leishmania infection by molecular biological methods. Am J Trop Med Hyg 2007, 77:324-329.

15. Prugnolle F, Durand P, Neel C, Ollomo B, Ayala FJ, Arnathau C, Etienne L, Mpoudi-Ngole E, Nkoghe D, Leroy E, Delaporte E, Peeters M, Renaud F: African great apes are natural hosts of multiple related malaria species, including Plasmodium falciparum. Proc Natl Acad Sci U S A 2010, 107:1458-1463.

16. Ogo NI, de Mera IG, Galindo RC, Okubanjo OO, Inuwa HM, Agbede RI, Torina A, Alongi A, Vicente J, Gortázar C, de la Fuente J: Molecular identification of tick-borne pathogens in Nigerian ticks. Vet Parasitol 2012, 187:572-577.

17. Bronsdon MA, Homer MJ, Magera JMH, Harrison C, Andrews RG, Bielitzki JT Emerson CL, Persing DH, Fritsche TR: Detection of enzoonotic babesiosis in baboons (Papio cynoephalus) and phylogenetic evidence supporting synonymy of the genera Entopolypoides and Babesia. J Clin Microbiol 1999, 37:1548-1553.

18. Raoult D, Fournier PE, Fenollar F, Jensenius M, Prioe T, de Pina JJ, Caruso G, Jones N, Laferl H, Rosenblatt JE, Marrie TJ: Rickettsia africae, a tick-borne pathogen in travelers to sub-Saharan Africa. N Engl J Med 2001, 344:1504-1510.

19. Kelly P, Matthewman L, Beati L, Raoult D, Mason P, Dreary M, Makombe R: African tick-bite fever: a new spotted fever group rickettsiosis under an old name. Lancet 1992, 340:982-983.

20. Kelly PJ, Beati L, Mason PR, Matthewman LA, Roux V, Raoult D: Rickettsia africae sp. nov., the etiological agent of African tick bite fever. Int I Syst Bacteriol 1996, 46:611-614.

21. Dumler JS, Barbet AF, Bekker CP, Dasch GA, Palmer GH, Ray SC, Rikihisa Y, Rurangirwa FR: Reorganization of genera in the families Rickettsiaceae and Anaplasmataceae in the order Rickettsiales: unification of some species of Ehrlichia with Anaplasma, Cowdria with Ehrlichia and Ehrlichia with Neorickettsia, descriptions of six new species combinations and designation of Ehrlichia equi and 'HGE agent' as subjective synonyms of Ehrlichia phagocytophila. Int J Syst Evol Microbiol 2001, 51:2145-2165.

22. Zhang L, Wang G, Liu Q, Chen C, Li J, Long B, Yu H, Zhang Z, He J, Qu Z, Yu J, Liu Y, Dong T, Yao N, Wang Y, Cheng X, Xu J: Molecular analysis of Anaplasma phagocytophilum isolated from patients with febrile diseases of unknown etiology in China. PLoS One 2013, 8:e57155-e57164.

23. Piesman J: Emerging tick-borne diseases in temperate climates. Parasitol Today 1987, 3:197-199.
24. Telford SR III, Gorenflot A, Brasseur P, Spielman A: Babesial infections in humans and wildlife. In Parasitic Protozoa. 5th edition. Edited by Kreier J. New York: Academic Press; 1993:1-47.

25. Benach JL, Coleman JL, Habicht GS, McDonald A, Grundwaldt E, Giron JA: Serological evidence for simultaneous occurrences of Lyme disease and babesiosis. J Infect Dis 1985, 152:473-477.

26. Dammin GJ, Spielman A, Benach $J$, Piesman J: The rising incidence of clinical Babesia microti infection. Hum Pathol 1981, 12:398-400.

27. Spielman A: Human babesiosis on Nantucket Island: transmission by nymphal Ixodes ticks. Am J Trop Med Hyg 1976, 25:784-787.

28. Goethert HK, Telford SR III: What is Babesia microti? Parasitol 2003 127:301-309.

29. Shih CM, Liu LP, Chung WC, Ong SJ, Wang CC: Human babesiosis in Taiwan: asymptomatic infection with a Babesia microti-like organism in a Taiwanese woman. J Clin Microbiol 1997, 35:450-454

30. Zamoto A, Tsuji M, Kawabuchi T, Wei Q, Asakawa M, Ishihara C: US- type Babesia microti isolated from small wild mammals in Eastern Hokkaido, Japan. J Vet Med Sci 2004, 66:919-926.

31. Zamoto A, Tsuji M, Wei Q, Cho SH, Shin EH, Kim TS, Leonova GN, Hagiwara K, Asakawa M, Kariwa H, Takashima I, Ishihara C: Epizootiologic survey for Babesia microti among small wild mammals in north eastern Eurasia and a geographic diversity in the beta-tubulin gene sequences. J Vet Med Sci 2004, 66:785-792.

32. Gray JS: Identity of the causal agents of human babesiosis in Europe. Int J Med Microbiol 2006, 296:131-136.

33. Masuzawa T, Suzuki H, Kawabata H, Ishiguro F, Takada N, Yano $Y$, Yanagihara $Y$ : Identification of spirochetes isolated from wild rodents in Japan as Borrelia japonica. J Clin Microbiol 1995, 33:1392-1394.

34. Cutler SJ, Abdissa A, Trape J-F: New concepts for the old challenges of African relapsing fever borreliosis. Clin Microbiol Infect 2009, 15:400-406.

35. Cutler SJ, Bonilla EM, Singh RJ: Population structure of East African relapsing fever Borrelia spp. Emerg Infect Dis 2010, 16:1076-1080.

36. Jowi JO, Gathua SN: Lyme disease: report of two cases. East Afr Med J 2005, 82:267-269.

37. Anderson NE, Mubanga J, Fevre EM, Picozzi K, Eisler MC, Thomas R, Welburn SC: Characterisation of the wildlife reservoir community for human and animal trypanosomiasis in the Luangwa Valley, Zambia. PLoS Negl Trop Disease 2011, 5:1211-1226.

38. Namangala B, Oparaocha E, Kajino K, Hayashida K, Moonga L, Inoue N, Suzuki Y, Sugimoto C: Preliminary investigation of trypanosomosis in exotic dog breeds from Zambia's Luangwa and Zambezi Valleys using LAMP. Am J Trop Med Hyg 2013, 89:116-118.

39. Ngure RM, Ndungu JM, Ngotho JM, Nancy MK, Maathai RG, Gateri LM: Biochemical changes in the plasma of vervet monkeys (Chlorocebus aethiops) experimentally infected with Trypanosoma brucei rhodesiense. J Cell Anim Biol 2008, 2:150-157.

40. Thuita JK, Kagira JM, Mwangangi D, Matovu E, Turner CMR, Masiga D: Trypanosoma brucei rhodesiense transmitted by a single tsetse fly bite in vervet monkeys as a model of human African trypanosomiasis. PLoS Negl Trop Dis 2008, 2:238-247.

41. Abenga JN, Anosa VO: Serum total proteins and creatinine levels in experimental gambian trypanosomosis of vervet monkeys. Afr J Biotechnol 2005, 4:187-190.

42. Cox-Singh J: Zoonotic malaria: Plasmodium knowlesi, an emerging pathogen. Curr Opin Infect Dis 2012, 25:530-536.

43. Yamasaki T, Duarte AMRC, Curado I, Summa MEL, Neves DVDA, Wunderlich G, Malafronte RS: Detection of etiological agents of malaria in howler monkeys from Atlantic Forests, rescued in regions of São Paulo city, Brazil. J Med Primatol 2011, 40:392-400.

44. Garnham P: Malaria Parasites and Other Haemosporidia. Oxford: Blackwell Scientific Publications; 1966.

doi:10.1186/s13071-014-0490-x

Cite this article as: Nakayima et al:: Detection and characterization of zoonotic pathogens of free-ranging non-human primates from Zambia. Parasites \& Vectors 2014 7:490. 